\title{
ANTONIN ARTAUD E JOSÉ SARAMAGO: CAOS E COSMOS ANTONIN ARTAUD AND JOSÉ SARAMAGO: CHAOS AND COSMOS
}

Recebido: 13/01/2021

Aprovado: $17 / 05 / 2021$

Publicado: $30 / 07 / 2021$

DOI: $10.18817 /$ rlj.v5i01.2586

Adeilton Lima Silva ${ }^{1}$
Orcid ID: https://orcid.org/0000-0002-4191-6678

Resumo: $O$ presente artigo analisa duas obras fundamentais para a compreensão de temáticas importantes da era industrial e tecnológica. Para Acabar com o Julgamento de Deus (1948), de Antonin Artaud e O Ano de 1993 (1975), de José Saramago. Propõe-se uma reflexão sobre a degradação humana, as guerras e invasões territoriais por recursos energéticos, os problemas ambientais associados à crise climática, à degradação social, econômica e política no planeta. Os paradoxos do avanço tecnológico e as suas consequências, como o desemprego e a fome, a reconfiguração das sociedades e os processos migratórios. Também os movimentos sociais, culturais e antirracistas diante da ascensão do neofascismo numa articulação com o conceito de necropolítica proposto pelo filósofo Achile Mbembe.

Palavras-chave: Necropolítica. Guerras. Humanidade. Neofascismo. crueldade.

Abstract: This paper analyzes two fundamental works for the understanding of important themes of the industrial and technological era. Para Acabar com o Julgamento de Deus (1948), by Antonin Artaud, and O Ano de 1993 (1975), by José Saramago. It proposes a reflection on human degradation, wars and territorial invasions for energy resources, environmental problems associated with the climate crisis, and social, economic, and political degradation on the planet. The paradoxes of technological advance and its consequences, such as unemployment and hunger, the reconfiguration of societies, and migratory processes. Also the social, cultural and anti-racist movements in the face of the rise of neofascism in an articulation with the concept of necropolitics proposed by the philosopher Achile Mbembe.

Keywords: Keywords: Necropolitics. Wars. Humanity. neo-fascism. cruelty.

Antonin Artaud (1948) e José Saramago (2010) são dois poetas referenciais para a produção artística e literária dos nossos tempos. Ambos implodiram, no século $X X$, estruturas liguísticas e convenções literárias, realizaram experiências estéticas e propuseram reflexões filosóficas fundamentais para a compreensão do pensamento racionalista herdado das grandes revoluções do passado e que muito influenciaram também a era da industrialização, do liberalismo econômico e dos avanços tecnológicos. As obras visionárias desses artistas em vários momentos vaticinaram a

\footnotetext{
${ }^{1}$ Adeilton Lima é ator e professor de literatura, teatro e cinema, com graduação em Letras, mestrado em Teoria Literária e doutorado em Artes, pela Universidade de Brasília. Há 32 anos, atua em Brasília onde é conhecido pelo trabalho direcionado para a poesia e pelos solos de investigação teatral como A Conferência, de sua própria autoria, Diário de um Louco, de Nicolai Gogol e Para Acabar com o Julgamento de Deus, de Antonin Artaud, que acaba de completar 26 anos de estrada. Estreou recentemente seu novo espetáculo Glauber Rocha, O Profeta do Delírio. Lançou, em 2016, seu primeiro livro de poesias com o título Sempre Diga Eu te Amo da Boca pra Dentro. E-mail: adeiltonator@hotmail.com
} 
crise estrutural que hoje a humanidade enfrenta. Os conflitos mundiais do último século e a hecatombe nuclear somam-se à crise humanitária, climática e sanitária dos nossos dias. Outros fatores que aumentam as tensões e a gravidade do mundo contemporâneo são os movimentos populacionais migratórios, a xenofobia e os preconceitos de gênero e raça, questões que nos preocupam diante do fortalecimento do neofascismo e da ascensão de um fenômeno social e político avassalador que o filósofo nigeriano Achile Mbembe define como necropolítica.

Atuando respectivamente no teatro e na literatura, realizaram obras que abrem novas perspectivas para a arte moderna, em confluência com o que de melhor já se produziu na França e em Portugal. Inovam em vários aspectos, desde a estruturação linguístico-formal à elaboração poética, de ritualísticas simbólicas ao mergulho no imaginário, trabalhando com mitos e arquétipos, projetando-se nos abismos do inconsciente, de forma a reconectar, de certa maneira, o homem, enquanto ser histórico e existencial, sem os artificialismos impostos pela razão. Tanto a psicanálise quando o surrealismo são referências vigorosas a permear a construção discursiva dessa literatura.

O diálogo entre estes dois profetas da modernidade é embasado pela tradição literária que atinge a maturidade em meio às mudanças técnico-científicas do final do século XIX. É aí que surgem os movimentos artísticos de vanguarda e onde vamos encontrar, na escola surrealista, principalmente, o ponto de intersecção para a análise aqui proposta, que é a de se fazer um estudo comparado entre os textos Para Acabar com o Julgamento de Deus, de Antonin Artaud (1948) e O Ano de 1993 (1975), de José Saramago. Como mencionado, outra referência dialógica em nosso percurso é o conceito de necropolítica, que de alguma forma já germinava nas poéticas desses autores, pois reflexo de um mundo em degeneração.

Fundado em 1924 por André Breton, tendo Artaud como um de seus principais nomes, o movimento surrealista é, entre as vanguardas europeias, uma das mais importantes experiências estéticas. Os princípios de construção poética desse movimento dão as bases de muitos elementos da produção literária contemporânea, também no teatro, artes plásticas e cinema. $\mathrm{O}$ ato criativo passa a ser processado a partir de procedimentos antiracionalistas. Propõe-se a desconstrução da lógica e, consequentemente, são questionados os valores filosóficos que contribuíram para a formação da cultura ocidental, materialista e liberal. O homem vê-se diante do inferno da existência, labiríntico e indecifrável. 
Não há modelo político, social ou filosófico capaz de amenizar a angústia existencial de finitude, de indicar caminhos ou de propor respostas. Os avanços tecnológicos, paradoxalmente, acabaram por aprisionar a natureza humana, artificializando e castrando sua essência. A metafísica cristã tornou-se um discurso vazio e da mesma forma que os demais sistemas, acabou também por se revelar como apenas um gueto ideológico a alimentar distopias.

Saramago não se filia necessariamente a uma escola ou grupo literário, contudo, sua escrita é frequentemente analisada pela crítica como pertencente a um historicismo fantástico, o que abre um leque para as referências acima já apontadas, de um simbolismo impactante, como veremos em O Ano de 1993.

O núcleo de reflexão dos textos aqui postos em diálogo explora com amplitude o quadro apocalíptico em que se encontra a humanidade da era tecnológica e do neocolonialismo. Guerras, violências, movimentos migratórios, crises ambientais, choques políticos, neofascismo e ascensão da extrema-direta no mundo. Tais conflitos, portanto, impactam e reconfiguram noções de territorialidades, desde o indivíduo, seu corpo, identidade e raça, assim como ao campo social, pertencimento, cultura e relações políticas. O conceito de necropolítica, discutido por Achile Mbembe, nasce exatamente da noção de soberania, considerando as tensões e os paradoxos entre o corpo individual e o Estado. Quais os limites de intervenção estatal no corpo individual? E por que a seleção direcionada principalmente para um determinado tipo de corpo ou grupo? Raça, cor da pele, condição social, gênero, etc.

\begin{abstract}
O exercício da razão equivale ao exercício da liberdade, um elementochave para a autonomia individual. Nesse caso, o romance da soberania baseia-se na crença de que o sujeito é o principal autor controlador do seu próprio significado. Soberania é, portanto, definida como um duplo processo de "autoinstituição" e "autolimitação" (fixando em si os próprios limites para si mesmo). O exercício da soberania, por sua vez, consiste na capacidade da sociedade para a autocriação pelo recurso às instituições inspirado por significações específicas sociais e imaginárias. (...) Minha preocupação é com aquelas formas de soberania cujo projeto central não é a luta pela autonomia, mas "a instrumentalização generalizada da existência humana e a destruição material de corpos humanos e populações". (MBEMBE, 2016, p. 124-125).
\end{abstract}

As duas obras aqui em análise, de alguma forma, nos trazem subsídios e referências sobre essas qustões que indicam um certo espiríto de época, que atravessa todo o século passado e impõe-se nas urgências da atualidade. Contudo, 
é importante notar que o caos apontado por Artaud e Saramago implode, inclusive, a necropolítica, estando toda a humanidade condicionada à violência, à peste e à morte, desta forma igualada ou reconhecível antropologica e primariamente pelos próprios dejetos.

O conceito de necropolítica artiula-se com os conceitos foulcautianos conhecidos como biopolítica e biopoder. O primeiro corresponde aos mecanismos de controle pelo Estado, pelo constituído, sobre os grupos sociais e sobre o indivíduo, nornalizando esse controle e introjetando nos indivíduos a necessidade de condicionamento a esse poder. A biopolítica é o cotidiano representado pelo grande olho ou por uma gigantesca marionete desde o espaço social à intimidade do indivíduo. O segundo, ou, mais precisamente, a outra face da moeda, é outo instrumento de controle sobre o tempo, o espaço e a psocilogia das pessoas, a uniformização das regras pela biolpoítica como socialização da obdiência. Tais elementos, perspassam as poéticas aqui estudadas, tanto no campo ficcional quanto nos aspectos estruturais atemporais de nossa sociedade apontados por tais alegorias.

O que notamos ao primeiro contato com os dois poemas narrativos é que $O$ Ano de 1993, até mesmo por ter sido escrito mais recentemente (1975), é a realização de uma profecia feita por Artaud, cujo texto Para Acabar com o Julgamento de Deus, data de 1948, escrito poucos meses antes de sua morte. Os dois textos são o que podemos definir como poemas-petardos, tamanho o impacto de suas vozes. A rigor, estão dentro do que o próprio Artaud chamava de "teatro da crueldade", significando tal expressão para o teatro ou para um determinado segmento da arte, inquieta e questionadora, como uma experiência de impacto, seja psicológico ou existencial, uma forma de eliminar o voyeurismo do espectador diante do acontecimento artístico.

Fiquei sabendo ontem, devo estar desatualizado ou então é apenas um boato, uma dessas intrigas divulgadas entre a pia e a privada, quando as refeições ingurgitadas são mais uma vez devidamente expulsas para a latrina. Fiquei sabendo ontem de uma das mais sensacionais dentre essas práticas das escolas públicas americanas, sem dúvida, daquelas responsáveis por esse país considerar-se na vanguarda do progresso. Parece que entre os exames e testes requeridos a uma criança que ingressa na escola pública, há o assim chamado: Teste do líquido seminal ou do esperma que consiste em recolher um pouco do esperma da criança recémchegada para ser colocado numa proveta e ficar à disposição para experimentos de inseminação artificial que posteriormente venham a ser feitos. (ARTAUD, 1983, p. 147). 
Ali, em 1948, em pleno pós-guerra, através deste discurso explosivo que por sinal sofreu perseguições e foi censurado, Artaud antecipa os procedimentos neocolonialistas dos norte americanos, os experimentos laboratoriais, guerras biológicas, invasões de territórios, derrubadas de democracias, etc. que irão vigorar ao longo do século XX no ocidente, referêncais que também constituem as bases da necropolítica e do biopoder da era tecnológica. Com esmagadora força poética, dessacraliza mitos de nossa época. Antevendo a política imperialista dos Estados Unidos e seus experimentos invasivos, seja no plano científico ou territorial, não deixa pedra sobre pedra na derrubada dos templos tecnológicos. Alerta para o fato de o homem estar caminhando cada vez mais para longe de sua natureza, à medida que destrói o planeta, cujas consequências, inevitavelmente, causarão o seu próprio extermínio. Ao falar dos experimentos laboratoriais, de forma contundente e explosiva, critica a artificialização da vida e defende como única possibilidade de sobrevivência da espécie humana, uma espécie de retorno às raízes da existência e cultura humanas. Não, contudo, uma negação do avanço tecnológico, mas uma chamada de atenção para o horror causado por muitas de suas consequências em relação á vida e ao meio ambiente. Dessa forma, defende os aspectos ritualísticos das culturas primitivas, da magia, explorando o simbólico e o imaginário, de forma a atingir o ser humano puro, em essência, ainda não contaminado pelos valores e vícios da sociedade, considerando, inclusive, as complexidades existenciais que envolvem o corpo humano, suas limitações e funcionamento. Um corpo extirpado pelos maniqueísmos políticos e industriais, porém, sedento de prazer, cultura e ritos.

Se quiserem, podem meter-me numa camisa de força, mas não existe coisa mais inútil que um órgão. Quando tiverem conseguido um corpo sem órgão, então o terão libertado de seus automatismos e devolvido sua verdadeira liberdade. Então poderão ensiná-lo a dançar às avessas como no delírio dos bailes populares e esse avesso será o seu verdadeiro lugar. (ARTAUD, op. Cit, p. 161-162)

Não se trata, evidentemente, de uma visão ingênua ou purista de uma civilização pré-colombiana, mas muito mais uma defesa de identidades culturais, da autonomia de um corpo social e cultural com sua austeridade e direito de existir com suas particularidades, ritos, e valores. O que Artaud discute, e que também veremos na confluência com Saramago, são as mazelas dos processos colonizadores e supostamente civilizatórios. As origens da necropolítica que hoje permeia a sociedade 
tecnológica residem exatamente aí. O que testemunhamos na atualidade é uma explosão de tensões históricas, em que os grupos tradicionalmente subjugados e excluídos resolveram reagir. Os fundamentos da necropolítica passam a ser confrontados.

É exatamente essa humanidade degradada que vamos encontrar no poema de José Saramago. Em sintonia com Artaud, o poeta descreve um universo de hecatombes, onde as pessoas rastejam consumidas pela miséria e pela peste. Sem dúvida, Saramago lança aí as sementes de seu arrebatador Ensaio Sobre a Cegueira (1995), grande sucesso editorial. Numa cidade destruída (nada mais que uma alegoria da descaracterização e da angústia do próprio homem) Saramago mostra a humilhante trajetória humana, procurando, em meio aos detritos produzidos pela técnica, resquícios do que de alguma forma lembrem o que fora a espécie. Expulso da civilização por sua própria cria (metaforicamente, tudo que gerou as guerras), partirá o homem em busca do elo perdido com a natureza. Vivendo um calvário miserável, sem sistemas ou ideais que lhe restituam a glória (?), só conseguirá reconhecer o outro, e a si mesmo, através do odor e da produção de excrementos. 0 ser reduzido à merda, o ser é nada, o ser e o nada. Existencialismo profundo nas cascas de um século adoecido pelas guerras, doenças e pelo capitalismo.

Nenhum lugar é suficientemente belo na terra para que doutro lugar nos desloquemos a ele

Mas uma razão haverá para que todas as horas do dia venham andando grupos de pessoas na direção da rua das estátuas

Estão dispensados os roteiros e os mapas uma vez que todos os caminhos vêm dar a esta rua e não a Roma onde ainda hoje não faltam as estátuas mas nenhuma que a estas se compare

Não é difícil chegar basta olhar o chão e seguir sempre pelos caminhos mais pisados também reconhecíveis pelas duas alas de excrementos que os ladeiam

O sol resseca-os rapidamente e se a chuva os desfaz nunca tanto que restitua o chão a uma qualquer virgindade

O homem aprendeu enfim a orientar-se sem bússola chega-lhe passar por onde outro homem passou antes

As pessoas vão conversando numerosamente e de vez em quando uma 
Neste mundo de horrores e sofrimentos, a multidão se movimenta como zumbis à deriva de sua própria sorte. Reconhecendo-se ainda como espécie apenas pelo odor de suas próprias fezes e excrementos.

Entretanto, como defende Artaud, a saída para a humanidade só será possível a partir da retomada dos mitos primitivos, através de um mergulho interior, num reencontro harmonioso com o ritual e os elementos da natureza. Em Saramago, é quando redescobre a magia e recupera a fertilidade que o homem reencontra a si mesmo e começa o retorno para a cidade, de onde fora expulso, reintegrando-se, portanto, ao processo existencial.

Depois choveu e a terra ficou subitamente verde com um enorme arco-íris que não se desvaneceu nem quando o sol se pôs

Nessa primeira noite ninguém dormiu toda a gente saiu das cidades para ver melhor as sete cores contra o fundo negríssimo do céu

E houve quem chorasse de joelhos na terra branda nas ervas que rescendiam do vertiginoso cheiro do húmus

E houve quem ininterruptamente cantasse uma extática melodia não ouvida antes que era o longo suspiro soluço da vida que nascendo se sufoca plena na garganta

E pelos campos fora arderam fogueiras altas que fizeram da terra vista do espaço um outro céu estrelado

E um homem e uma mulher caminharam entre a noite e as ervas naturais e foram deitar-se no lugar precioso onde nascia o arco-íris (SARAMAGO, op.cit. 118 - 19).

Ambos os poemas fazem um percurso que vai do universo noturno para o universo diurno da narrativa. ${ }^{3}$ Alguns aspectos são especialmente marcantes na construção poética de Artaud e de Saramago. Nota-se a duplicidade de vozes nos dois poemas, ou seja, enquanto Artaud trabalha com o duplo da lucidez e da loucura, Saramago revela a ótica de testemunha e protagonista dos acontecimentos. Se em Para acabar com o julgamento de Deus é difícil notar tal dicotomia, em O Ano de 1993 já é mais nítida a construção narrativa em terceira e primeira pessoas.

No plano temático, ambos utilizam-se com precisão de alguns elementos que revelam a força da simbologia e beleza narrativas. São eles: o esperma, a merda, a

\footnotetext{
${ }^{2}$ Formatação conforme o texto original.

${ }^{3}$ Conf. Gilbert Duran. As Estruturas Antropológicas do Imaginário.
} 
dor, a linguagem e o ritual. Ao confrontarmos os dois poemas em relação a estes pontos temáticos, notamos que a forma explorada traduz a seguinte trajetória: degradação, sofrimento, renascimento e purificação.

Onde cheira a merda, cheira a ser. O homem podia muito bem não cagar, não abrir a bolsa anal. Mas preferiu cagar, assim como preferiu viver em vez de aceitar viver morto, pois para não fazer cocô teria que consentir em não ser, mas ele não foi capaz de se decidir a perder o ser, ou seja, a morrer vivo. (ARTAUD, op.cit. p.151)

No entanto o belo final de cada um dos poemas dá a dimensão exata do que é e do que pode significar a busca desesperada do homem por respostas:

O homem é enfermo porque é mal construído. Temos que nos decidir a desnudá-lo para raspar esse animalúculo que o corrói mortalmente, Deus, e juntamente com Deus os seus órgãos. Se quiserem, podem meter-me numa camisa de força, mas não existe coisa mais inútil que um órgão. Quando tiverem conseguido um corpo sem órgãos, então o terão libertado dos seus automatismos e devolvido sua verdadeira liberdade. Então poderão ensinálo a dançar às avessas como no delírio dos bailes populares e esse avesso será seu verdadeiro lugar. (ARTAUD, op.cit. p. 161-162).

(...) Uma vez mais os lugares conhecidos os lugares de solidão e de morte os centímetros quadrados de tortura as cores do sangue até à sua final cor de terra

(...)

Uma vez mais (...) O ombro sobre o ombro

O corpo sobre o corpo

A ida e o regresso $O$ impossível ficar ou $A$ simples memória de ter sido

( ) E uma criança objetiva se aproxima e estende as mãos para a sombra que retém o contorno ainda mas não já o cheiro do corpo sumido (...) consoante se conclui dc nada haver debaixo da sombra que a criança levanta como uma pele esfolada (SARAMAGO, op.cit. $124-125$ ).

Enquanto Artaud somente vê como possibilidade de saída para o homem, a transcendência para o interior de si mesmo, sendo essa, como já mencionamos a única forma de se evitar sua decadência enquanto resgate da essência de sua natureza, Saramago finaliza seu poema com um quadro mais assustador que o do início. O homem já não tem mais essência, já não tem mais ser, já deixou de existir. Só resta, porém, recomeçar o ciclo.

Loucos, visionários, lúcidos e perseguidos. As páginas de poesia e história escritas por esses homens vão aos poucos revelando, ao passar do tempo, a verdade terrível que as contém. Delas vemos projetar-se um amplo e profundo sentido de 
crueldade. Para Artaud, no entanto, em um de seus textos de O Teatro e Seu Duplo (1993) sobre este tema, em oposição ao sentido material, sádico e violento, crueldade adquire outro sentido.

Sentido de apetite, de vida, rigor cósmico e necessidade implacável, no sentido gnóstico de turbilhão de vida que devora as trevas, no sentido dessa dor fora de cuja necessidade irrelutável a vida não consegue se manter; o bem é desejado, é o resultado de um ato, o mal é permanente (...) É com crueldade que se coagulam as coisas, que se formam planos do criado. $\mathrm{O}$ bem está sempre na face externa, mas a face interna é um mal. ^íal que será reduzido com o passar do tempo, mas naquele instante supremo em que tudo que existiu estiver prestes a retomar ao caos. (ARTAUD, 1993, p. 93).

Há vida, há possibilidades, há caminhos. A recente ascensão do neofascismo e a consequente expansão de necropolíticas têm gerado, todavia, contrapontos importantes, movimentos de lutas e resistências por parte de forças progressistas em todo o mundo. O ciclo do caos e do ódio parece chegar ao fim.

As discussões em torno da grave crise climática e também em relação aos movimentos migratórios têm tomado corpo nos parlamentos políticos mundo afora, assim como nas pautas da Organização das Nações Unidas (ONU). O momento é de uma profunda reflexão sobre as possibilidades de preservação da vida sobre o planeta, situação crucial na revisão e buscas de outras fontes de energia associadas a novos padrões econômicos de sustentabilidade. Nas entrelinhas das obras aqui apresentadas um sopro de esperança, tal como a alegria do ritual em torno de uma fogueira celebrando a vida numa dança ofertada aos deuses. Do caos ao cosmos!

\section{Referências Bibliográficas}

ARTAUD. Antonin. Para Acabar Com o Julgamento de Deus. In: Escritos de Antonin Artaud. Coleção Rebeldes Malditos. Porto Alegre: L e PM, 1983.

Fontes, 1993.

O Teatro e Seu Duplo. Org. Teixeira Coelho, São Paulo: Ed. Martins

DURAND, Gilbert, GODINHO, Hélder. As Estruturas Antropológicas do Imaginário: Introdução a Arquetipologia Geral. São Paulo: Martins Fontes, 2002.

ESSLIN, Martin. Artaud. São Paulo: Ed. Cultrix, 1978.

MBEMBE, Achille. Necropolítica. Melusina, 2011.

SARAMAGO, José. O Ano de 1993. Porto: São Paulo: Cia Das letas, 1991. 
letras, 2008.

. Saramago, José. Ensaio sobre a cegueira. São Paulo: Cia das

Necropolítica: o que esse termo significa? disponível em:

https://www.politize.com.br/necropolitica-o-que-e/.

Revista: Necropolítica. In: Arte \& Ensaios / revista do ppgav/eba/ufrj| n. 32 | dezembro, 2016. 